\title{
EDITORIAL
}

\section{What's bad for the gander... Women and sudden cardiac death}

\author{
W J Groh, E von der Lohe, D P Zipes
}

Heart 2002;88:553-554

The risk of sudden cardiac death seems to be increasing in women, such that the two sexes may soon reach parity when it comes to $\mathrm{SCD}$

$\mathrm{S}$ udden cardiac death (SCD), typically defined as death from a cardiac cause that occurs within one hour of the onset of symptoms in an individual without a prior condition that would appear fatal, remains a major health problem in the developed world. ${ }^{1}$ SCD accounts for more than $60 \%$ of all cardiac deaths, with absolute numbers in the USA well in excess of 400000 annually. $^{2}$ The majority of SCD occur in the setting of coronary heart disease (CHD) and thus populations with this condition often form the basis for SCD risk assessment.

A truism regarding SCD in the setting of CHD has been that women are at a significantly lower risk than men. In the Rochester $\mathrm{CHD}$ project women presenting with angina, despite being an average of seven years older than men presenting with angina, had only half the risk of dying in the subsequent 10 years as men. ${ }^{4}$ In the Framingham study cohort with outcome data ascertained over almost four decades, women with CHD had a quarter of the risk of SCD as men. ${ }^{5}$ In those with documented myocardial infarction, the age adjusted annual rate of SCD was 4.6 per 1000 in women and 17.5 per 1000 in men.

\section{AGE AND SEX DIFFERENCES IN SCD}

A paper by Abildstrom and colleagues in the current issue of Heart provides disconcerting data that women may be unfortunately achieving equality with men in SCD incidence in the setting of CHD. ${ }^{6}$ The paper reports mortality results in 5983 unselected, consecutive patients discharged alive from hospital after myocardial infarction. The registry data were collected from 27 Danish coronary care units initially to identify patients for a placebo controlled, randomised trial (trandolapril cardiac evaluation (TRACE) study) of the angiotensin converting enzyme inhibitor trandolapril. ${ }^{7}$ The current paper analyses the registry mortality data primarily with regards to age and sex and differentiates SCD and non-SCD using standard criteria. Not surprisingly, increasing age was found to lead to an increasing risk of both SCD and non-SCD. What is surprising as compared to previous studies is that the age corrected incidence of SCD was only 1.3 times higher in men than women. Women over the age of 66 years had a large three year SCD mortality rate of greater than $10 \%$.
46202, USA

wgroh@iupui.edu
The study does not really help us in discovering what factors were present in these women that might have led to the high SCD incidence. We are informed that the typical characteristics predicting excessive mortality post-myocardial infarction (decreased wall motion index, congestive heart failure, etc) were independently associated with SCD and non-SCD in this study, but a subgroup analysis differentiating these findings between men and women is not provided. Whether these unanalysed characteristics could account for some or all of the higher risk of SCD in these Danish women as compared to earlier studies remains unknown.

Other aspects about the Danish registry require some explanation before the results can be assumed to apply to other populations in the developed world. For an unselected, all comers, post-myocardial infarction population the mortality rate was astoundingly high. The annual rate of SCD in the Danish study was approximately three times that observed in the Framingham registry that was conducted primarily in a pre-thrombolytic era. ${ }^{5}$ The total mortality rate in the Danish study exceeded that observed in both the European (EMIAT) and Canadian (CAMIAT) post-myocardial infarction amiodarone trials. ${ }^{89}$ Both of these studies were conducted in a high risk subgroup and one would anticipate higher mortality rates than observed in a study done in unselected post-myocardial infarction patients.

\section{HIGH RISK PATIENTS}

The high mortality rate in the Danish registry is less surprising if one examines how sick these patients were. Abildstrom and colleagues report that $49 \%$ of the registry population manifested congestive heart failure. ${ }^{6}$ In the GISSI-2 study, evaluating thrombolytic treatment for myocardial infarction, the congestive heart failure prevalence was six times less at $8.3 \% .^{10}$ Almost $40 \%$ of the Danish registry group met criteria for inclusion in the TRACE study with a post-myocardial infarction echocardiographic ejection fraction of $\leqslant 0.35$. Again, comparing this to the GISSI-2 population where just $13 \%$ had an ejection fraction of $\leqslant 0.35$, one can understand what a high risk group was studied in the Danish registry. Understanding how ill these Danish

Abbreviations: CAMIAT, Canadian amiodarone myocardial infarction arrhythmia trial; $C H D$, coronary heart disease; EMIAT, European myocardial infarct amiodarone trial; SCD, sudden cardiac death; TRACE, trandolapril cardiac evaluation 
patients were after their myocardial infarction makes one increasingly interested in how they were treated. We know only that $43 \%$ overall received thrombolysis. We are not informed how the patients were risk stratified, what proportion received coronary angiography, percutaneous coronary intervention, or coronary artery bypass surgery, or what pharmacological therapies were given during the recovery period. We do know that a moderate proportion (876 patients) received trandolapril in the TRACE study. Those receiving trandolapril had a $22 \%$ lower risk of total mortality. ${ }^{7}$ Did the beneficial effects of the angiotensin converting enzyme inhibitor lead to the addition of this treatment for those initially randomised to placebo? Again, we cannot ferret out this information from that provided in the registry report.

Despite the difficulty in interpreting the results of the Danish registry this paper supports a growing body of evidence that women are increasingly at a higher risk of a poor outcome after myocardial infarction, especially in the unfortunate outcome of SCD. We already know that women have a higher in-hospital mortality rate after myocardial infarction than men, with the greatest inequality observed in younger women. ${ }^{11}$ SCD in women, like men, is primarily a sequelae of acute or chronic coronary heart disease. ${ }^{12}$ In the USA, over a nine year period from 1989 to 1998, the risk of SCD decreased in both sexes, but the relative decrease in women was only about half that of the men. ${ }^{2}$ Disturbingly, SCD risk actually increased over this period in younger women by $21 \%$. Women are more likely to suffer SCD occurring out-of-hospital than men. Women with out-of-hospital cardiac arrest are less likely to be resuscitated, probably related to a lower likelihood of being found in the treatable rhythm of ventricular fibrillation. ${ }^{13}$ In an unpublished analysis of out-of-hospital cardiac arrest occurring in rural Indiana in the USA, women were less likely to have a witnessed arrest than men, were in ventricular fibrillation half as frequently as men, and had a call-to-shock interval if ventricular fibrillation was present of 2.6 minutes longer than men. ${ }^{14}$ These differences resulted in a survival to hospital discharge rate in women of only $2.2 \%$, less than a third of that observed in men.

It is clear that in the area of SCD risk women are rapidly achieving equality with men. What is not clear is what (if anything) we as medical providers can do to curb this disturbing development.

\section{Authors' affiliations}

W J Groh, E von der Lohe, D P Zipes, Department of Medicine, Krannert Institute of Cardiology, Indiana University, Indianapolis, Indiana, USA

\section{REFERENCES}

1 Zipes DP, Wellens HJ. Sudden cardiac death. Circulation 1998;98:2334-51

2 Zheng ZJ, Croft JB, Giles WH, et al. Sudden cardiac death in the United States, 1989 to 1998. Circulation 2001;104:2158-63.

3 Myerburg RJ, Kessler KM, Castellanos A. Sudden cardiac death. Structure, function, and time-dependence of risk. Circulation 1992;85:12-10.

4 Orencia A, Bailey K, Yawn BP, et al. Effect of gender on long-term outcome of angina pectoris and myocardial infarction/sudden unexpected death. JAMA 1993;269:2392-7.

5 Kannel WB, Wilson PW, D'Agostino RB, et al. Sudden coronary death in women. Am Heart J 1998;136:205-12.

6 Abildstrom SZ, Rask-Madsen C, Ottesen MM, et al. Impact of age and sex on sudden cardiovascular death following myocardial infarction. Heart 2002;88:573-8.

7 Kober L, Torp-Pedersen C, Carlsen JE, et al. A clinical trial of the angiotensin-converting-enzyme inhibitor trandolapril in patients with left ventricular dysfunction after myocardial infarction. Trandolapril cardiac evaluation (TRACE) study group. N Engl J Med 1995;333:1670-6.

8 Cairns JA, Connolly SJ, Roberts R, et al. Randomised trial of outcome after myocardial infarction in patients with frequent or repetitive ventricular premature depolarisations: CAMIAT. Canadian amiodarone myocardial infarction arrhythmia trial investigators. Lancet 1997;349:675-82.

9 Julian DG, Camm A, Frangin G, et al. Randomised trial of effect of amiodarone on mortality in patients with left-ventricular dysfunction after recent myocardial infarction: EMIAT. European myocardial infarct amiodarone trial investigators. Lancet. 1997:349:667-74.

10 Maggioni AP, Zuanetti G, Franzosi MG, et al. Prevalence and prognostic significance of ventricular arrhythmias after acute myocardial infarction in the fibrinolytic era. GISSI-2 results. Circulation 1993;87:312-22.

11 Vaccarino V, Parsons L, Every NR, et al. Sex-based differences in early mortality after myocardial infarction. National registry of myocardial infarction 2 participants. N Engl J Med 1999;341:217-25.

12 Burke AP, Farb A, Malcom GT, et al. Effect of risk factors on the mechanism of acute thrombosis and sudden coronary death in women. Circulation 1998;97:2110-16.

$13 \mathrm{Kim}$ C, Fahrenbruch CE, Cobb LA, et al. Out-of-hospital cardiac arrest in men and women. Circulation 2001;104:2699-703.

14 Groh WJ, Newman MM, Beal PE, et al. Limited response to cardiac arrest by police equipped with automated external defibrillators: lack of survival benefit in suburban and rural Indiana - the police as responder automated defibrillation evaluation (PARADE). Acad Emerg Med 2001;8:324-30. 